\title{
Investigating Ways to Use Facebook at the University Level: A Delphi Study
}

\author{
Michael J. Magro \\ Shenandoah University, Harry \\ F. Byrd, Jr. School of \\ Business, Winchester, VA, USA \\ mmagro@su.edu \\ Katie Ryan \\ BlueCross BlueShield of \\ Texas, \\ Dallas, TX, USA
}

katie.traveller@gmail.com

\author{
Jason H. Sharp \\ Tarleton State University, \\ College of Business, \\ Stephenville, TX, USA
}

jsharp@tarleton.edu

\author{
Sherry D. Ryan \\ University of North Texas, \\ College of Business, \\ Denton, TX, USA
}

sherry.ryan@unt.edu

\begin{abstract}
Social networking sites have experienced tremendous growth and have become an integral part of the daily lives of a large portion of the population, both in the United States, as well as worldwide. Whereas a vast majority of university students $\log$ in to Facebook every day, both research and implementation of Facebook as a learning tool in higher education is lacking. This study investigates the question, "How can Facebook be used to enhance educational experiences beyond the traditional classroom?" To facilitate this research a multi-round Dephi study was conducted among students from a southwestern university in the United States with the purpose of generating and ranking ideas regarding the use of Facebook at the university level. Results are reported and discussion and conclusions are presented.
\end{abstract}

Keywords: Social networking, education, Facebook, Delphi method

\section{Introduction}

Over the past decade SNSs (Social Network Sites) have grown exponentially. The SNS that has experienced the greatest growth and continues to be the most widely used around the world is Facebook. In 2009, the total number of active Facebook users stood at 150 million with half of

Material published as part of this publication, either on-line or in print, is copyrighted by the Informing Science Institute. Permission to make digital or paper copy of part or all of these works for personal or classroom use is granted without fee provided that the copies are not made or distributed for profit or commercial advantage AND that copies 1) bear this notice in full and 2) give the full citation on the first page. It is permissible to abstract these works so long as credit is given. To copy in all other cases or to republish or to post on a server or to redistribute to lists requires specific permission and payment of a fee. Contact Publisher@InformingScience.org to request redistribution permission. those users reported to be logging in at least once a day (Zuckerberg, 2009). Worldwide, only Google, Microsoft, and Yahoo were larger Internet sites than Facebook at that time (Schonfeld, 2009). However, in terms of weekly U.S. traffic it did not take long for Facebook to overtake Google doing so in March 2010 with a reported membership exceeding 500 million (Hardawar, 2010). The growth of Facebook continued with 
membership increasing to 750 million members in mid 2011 (Facebook Press Release, Timeline). And, on October 4, 2012, Mark Zuckerberg (2012) announced that "there are more than one billion people using Facebook actively each month".

Although the original intent of Facebook was to connect college students with one another, its worldwide impact can be seen by the fact that it has been translated into over 100 languages (Smith, 2010). In its inception only those with an approved email address with an ".edu" domain name were eligible. Due to this limitation, 18-24 year olds made up the original demographic. However, since Facebook has opened up to individuals outside of the ".edu" domain, other demographic areas are increasing rapidly (Facebook Press Release, Statistics); albeit in the U.S., the majority of SNS users continues to be teens and young adults (Lenhart, 2009). Going forward there does not appear to be any intention to limit its growth as Zuckerberg (2012) noted on the website, "I am committed to working every day to make Facebook better for you, and hopefully together one day we will be able to connect the rest of the world too".

Learning management systems (LMS) have been utilized in educational settings for many years. According to the Gilfus Education Group (2012), the top five LMSs for 2011-2012 are the following: Blackboard, Desire2Learn, Moodle, Adrenna Academic, and Sakai Open Academic Environment. All are designed to support the instructor and to allow some degree of collaboration between students. Moodle is open source and completely free whereas the latter two are built on open source platforms. Other standard communication methods include traditional e-mail, and communication platforms such as Google's gmail which includes instant messaging and video conferencing. Still, an argument can be made that for collaborative teaching and learning, SNSs such as Facebook, may be a better match for today's students than more traditional pedagogi$\mathrm{cal} /$ andragogical tools (Salavuo, 2008). First, students are comfortable communicating via an SNS because a large number are already using one in their personal lives. Second, students have come to expect a certain amount of media richness of their technologies, preferring videos, photographs, and graphics to be a part of their learning experience to enhance community building through increased interpersonal knowledge. Often times, a SNS will provide much greater and robust support for multimedia formats than traditional LMS. Third, through the creation of personal profiles students can potential identify others with similar interests and certain areas of expertise, leading to collaborative learning opportunities and sharing of ideas and knowledge. Fourth, with the explosion of mobile devices (e.g., smart phones, pad computing) students have a growing expectation of mobile access. Although some LMSs are now offering mobile applications (e.g., Blackboard, Moodle), functionally speaking, Facebook tends to be much more robust. To some degree they are simply web sites with a front-end that appears like an app, but not providing a true app experience, with full functionality, like the Facebook mobile app. Additionally, the Facebook mobile app is available for free, whereas some LMSs are moving away from providing a free app to charging a fee, unless the app is licensed by the school. Finally, the end of the semester does not limit the student's access to the course material if a SNS is utilized as opposed to a course-related LMS (Magro, Ryan, Sharp, \& Ryan, 2009).

\section{Past Uses of Social Network Sites in Education}

Despite the fact that Facebook continues to be one of the most popular and widely used SNSs among college students the number of empirical studies examining its use in higher educational settings is under represented in the literature (Magro, Ryan, Ryan, \& Sharp, 2012). Those studies that have been conducted can be classified into the following categories: 1) student and faculty interactions, 2) the effect of student individual differences on adoption and usage, 3) student-tostudent collaboration, and 4) SNS impact on individual learning. In this section we discuss representative literature from each category. 
Magro, Sharp, Ryan \& Ryan

\section{Student-Faculty Interactions}

A first area of student-faculty interactions studied the impact of faculty self-disclosure on student motivation, affective learning, and classroom climate when utilizing Facebook (Mazer, Murphy, $\&$ Simonds, 2007). Based upon the level of faculty self-disclosure (high, medium, low) via Facebook features, the results of the study showed statistically significant differences across these different levels, suggesting that the higher the level of self-disclosure on the part of the instructor results in higher levels of motivation and affective learning in addition to a more positive environment in the classroom. The findings were a result of one-way ANOVAs conducted on each of the items listed above with significant differences revealed as described below:

- Between the high self-disclosure and low self-disclosure conditions, $F(2,127)=8.05, \mathrm{p}$ $=.001, \eta^{2}=.11$. Participants in the high self-disclosure condition $(\mathrm{M}=81.09, \mathrm{SD}=$ 12.12) reported significantly higher levels of anticipated motivation than participants in the low self-disclosure group $(\mathrm{M}=70.62, \mathrm{SD}=11.88)($ p. 9).

- Between high self-disclosure and low self-disclosure conditions and the medium selfdisclosure and low self-disclosure groups, $F(2,130)=6.35, \mathrm{p}=.004, \eta^{2}=.07$. Participants in the high self-disclosure condition $(\mathrm{M}=45.09, \mathrm{SD}=6.70)$ reported higher levels of anticipated affective learning than participants in the low self-disclosure condition (M $=38.82, \mathrm{SD}=8.54)$ and those in the medium self-disclosure condition $(\mathrm{M}=43.64, \mathrm{SD}=$ 10.41) reported higher affective learning scores than those in the low self-disclosure condition $(\mathrm{M}=38.82, \mathrm{SD}=8.54)$ (p. 9).

- Between high self-disclosure and low self-disclosure conditions and the medium selfdisclosure and low self-disclosure groups, $F(2,129)=11.74, \mathrm{p}=.000, \eta^{2}=.13$. Participants in the high self-disclosure condition $(\mathrm{M}=34.36, \mathrm{SD}=3.31)$ reported higher anticipated classroom climate scores than participants in the low self-disclosure condition $(\mathrm{M}=$ $30.74, \mathrm{SD}=4.22)$ and those in the medium self-disclosure condition $(\mathrm{M}=33.70, \mathrm{SD}=$ 3.56) reported higher anticipated classroom climate scores than those in the low selfdisclosure condition $(\mathrm{M}=30.74, \mathrm{SD}=4.22)($ p. 10).

Given these findings, the instructor should carefully evaluate the extent to which they selfdisclose to impact the students in a positive manner without crossing any personal boundaries. The findings of Lam (2012) support the importance of the instructor's support and use of Facebook in that "in order to have the interaction benefit from Facebook, teachers should be active and interactive sufficiently to show their participation and involvement online" (p. 383). Lam goes on to say that active participation of the instructor fosters greater student-faculty interaction and subsequently improves student motivation in learning.

Communication is also a crucial element of student-faculty interaction. Another study used the Facebook instant messaging feature to offer virtual office hours as an additional means of communication beyond face-to-face office hours (Li \& Pitts, 2009). The study found that levels of satisfaction among students were higher for those students in classes where virtual office hours were offered in addition to face-to-face office hours over classes that just offered face-to-face office hours. The authors hypothesized that "evening students are more likely to use virtual office hours than daytime students" (p. 177) and that the "overall satisfaction with office hours of students who enrolled in classes offering virtual office hours will be higher than the overall satisfaction with office hours of students who enrolled in classes that do not offer virtual office hours" ( $p$. 178). The study consisted of pre-study survey and post-study survey administered at the beginning and end of the semester, respectively. Based upon an analysis of the post-study data, the results indicated that the first hypothesis was not supported, that evening students are more likely to use virtual office hours than daytime students. However, based upon an analysis of the post-study data the "average satisfaction of participants in classes that offered virtual office hours was higher 
than the classes without virtual office hour setting: 4.55 vs. 4.17" (p. 180). A t-test was conducted on the satisfaction value of each individual student between classes with and without virtual office hours and a significant difference was found between the two groups $(\alpha=0.1, p=0.074$, one-tail test), supporting the second hypothesis. Overall, perceptions among students were positive toward the virtual office hours and indicated a strong predilection for communicating with their faculty using Facebook. Finally, students did indicate that they would like virtual office hours added to future classes. This is a good example of the fact that students are familiar and comfortable using the communication features of Facebook and are willing to expand their use within educational settings.

\section{Student-To-Student Collaboration}

Not only is student-faculty interaction important in educational settings, but it is also crucial for students to learn to collaborate with one another. One way this was implemented was to use Facebook to assist first semester doctoral students adapt not only to their Ph.D. program, but to acclimate to a new national culture through collaborative discussions (Ryan et al., 2011). Using an autoethnography method, the instructor of the course posted a weekly tip related to important components of a Ph.D. program as well as cultural topic. Students would then post discussions, observations, and/or questions. When the semester concluded the students posted their thoughts about participating in such a collaborative setting using Facebook. The results of the study indicated that Facebook did contribute to collaborative knowledge exchange in multiple ways. Anxiety related to starting a $\mathrm{Ph} . \mathrm{D}$. program, adjusting to a new national culture, and promoting socialization and community appeared to be reduced.

Similar to Ryan et al. (2011), Irwin, Ball, Desbrow, and Leveritt (2012) were interested in how the use of a course Facebook page would potentially effect the communication and collaboration between students. They hypothesized that the course Facebook page would be widely used and increase the communication and collaboration between students. The study included courses at both the undergraduate and graduate levels. Two questionnaires were administered in the first and last class meetings of the course, respectively. The results of the first questionnaire reported that a large percentage of the 161 respondents had an active Facebook account, 93.1\%. The results also indicated that a good portion of the respondents, $78 \%$, thought that the course Facebook page would indeed help facilitate learning by increasing the communication and interaction among students. When the responses of the second questionnaire were analyzed it was discovered that $81.9 \%$ of the 110 respondents actually engaged in some manner with the course Facebook page. However, just over half, $51 \%$ of respondents perceived that the course Facebook page was effective in contributing to their learning experience. Interestingly, $76.4 \%$ of respondents still indicated that they would recommend using Facebook pages for future courses. Based upon these findings, the authors suggested that Facebook as a learning aid has "potential to promote collaborative and cooperative learning" (p. 1221).

Students also collaborated on a student project to foster more interest in their school's basketball games (Williams \& Chinn, 2009). Using Web 2.0 tools the students worked in teams to create projects and generate interest. By using tools such as Facebook, YouTube, etc., the students learned important concepts related to social media, but more importantly how to work together and apply these technologies in a real-life project. Amazingly, via a structured plan and the use of these various social media applications attendance at basketball games increased $200 \%$. This is a good example of how social media-related technologies, like Facebook, can be utilized to stimulate experiential learning and teamwork in the classroom.

In each case where Facebook has been implemented to help increase the collaboration between students it is important to consider the motivational factors, whether intrinsic or extrinsic, that encourage the students to use the SNS for this purpose. In terms of extrinsic motivation, partici- 
Magro, Sharp, Ryan \& Ryan

pation points may be awarded as a part of the course grade for utilizing the collaborative tools. Related to intrinsic motivation, McCarthy (2012) indicated that the "more personalized the social networking site's presence, the greater the motivation of students to participate and learn course material" (p. 759).

\section{The Effect of Student Individual Differences on Adoption and Usage}

In addition to student-faculty interaction and student-to-student collaboration, another area of research is related to the adoption and usage of Facebook on an individual student level. Specifically the personality traits of neuroticism, extraversion, openness to experience, agreeableness, and conscientiousness have been studied (Ross, Orr, Sisic, Arseneault, Simmering, \& Orr, 2009). Surprisingly, it was found that relatively few significant relationships existed between the above mentioned traits and the use of Facebook. For example, the authors put forth that students scoring high on neuroticism would spend more time on Facebook, share more personal information, and send fewer private messages. However, this did not prove to be the case. Those scoring high on extroversion did participate in significantly more groups $(\mathrm{M}=14.81, \mathrm{SD}=11.11)$ as opposed to those scoring low on extroversion $(\mathrm{M}=7.94, \mathrm{SD}=5.83), \mathrm{t}(42)=2.44, \mathrm{p}=.019, \mathrm{~d}=0.75$, but showed no statistically significant differences in regard to number of friends, time spent online, or use of communication tools. Finally, in regard to agreeableness, openness to experience, and conscientiousness no statistically significant differences were found. In a another study related to personality traits (Orr, Sisic, Ross, Simmering, Arsenault, \& Orr, 2009), a correlation matrix was used to examine the association between shyness, time spent on Facebook, number of Facebook friends, and attitudes toward Facebook. The results indicated that shyness was significantly negatively correlated with the number of Facebook "friends" (-.25, p $<0.05$, two-tailed). In general, it appears that the impact of personality traits on Facebook usage is less significant than may have been originally thought.

Related to the issue of personal traits, some researchers believe that "social traits are more important than individual internal traits, for their influence on interpersonal interactions within a community such as Facebook" (Wu, Wang, Liu, Hu, and Hwang, 2012, p. 251). In a study conducted among 415 respondents, 52.4\% which self-identified as university level students they hypothesized that there is a positive relationship between social self-efficacy and social trust as well as a positive relationship between social trust and social capital. Structural equation modeling was conducted and an analysis of the data indicated support of their hypotheses as indicated: social self-efficacy was positively associated with social trust, $r(\gamma 11=.13 ; \mathrm{p}<.05)$, social trust had a positive impact on bonding capital, $\mathrm{h}(\beta 21=.94 ; \mathrm{p}<.0001)$, social trust was positively related to bridging, $(\beta 22=.92 ; \mathrm{p}<.0001)$, social trust mediated the relationship between social self-efficacy and bonding social capital, and social self-efficacy to bridging social capital was .12 $(\mathrm{p}<, 05)$. In sum, more so than individual personality traits, "the individual's social self-efficacy affects their social trusts, thereby influencing their social capital on Facebook environment" (p. 251). The further asserted that the most fundamental requirement for interpersonal interaction is social trust, "particularly so in an onlinecommunity because deception is so much easier where people do not meet face-to-face" (p. 251). Due to the fact that so many universities are offering online degree program where students never meet face-to-face, these social traits may become more and more relevant to effective use of Facebook in higher education.

\section{SNS Impact on Individual Learning}

Also at the individual student level, studies have been conducted related to the impact of SNS on individual learning, in particular self-efficacy has been studied in the context of using Facebook as a motivational tool (Bowers-Campbell, 2008). The main argument made by the author is that 
certain features of Facebook have the potential to help students who are struggling with low selfefficacy and poor self-regulation behaviors that traditionally characterize developmental learning students. A specific feature was groups, which provides the student with a good deal of control for defining their own learning goals. The study indicated that Facebook can be used to foster a better sense of connection between instructor and students even before the class begins through the use of personal profiles. This connection appeared to help break down the self-efficacy barrier by building confidence in the student because they felt they knew their instructor better. In sum, through the use of Facebook students developed a stronger sense of control and improvement on course outcomes.

Also related to motivation, Lam (2012) examined four benefits of using Facebook in an educational setting and postulated that each of these should positively influence student motivation in learning. The four benefits included: interaction, communication, social relationship, and participation. A questionnaire was distributed to 312 students with a total of 284 students responding for a response rate of $91.0 \%$. Multiple regression analysis was conducted using the benefits listed above as independent variables, while student learning motivation was used as a dependent variable. The results indicated that a statistically significant relationship existed between all four variables and student learning motivation, with participation having the highest correlation. The author summarizes each benefit as follows below. The interaction benefit exists both between other students as well as the instructor. The instructor is the catalyst for fostering this interaction. As the instructor is more supportive of and involved in the use of Facebook tools, so the students will be more inclined to use them and benefit from the additional interaction. The communication benefit is similar in that the instructor leads the students. As the instructor communicates via the Facebook tools it encourages students to do the same. The social benefit of Facebook can also be experienced within the classroom to some degree as well and appears to have a positive benefit on student motivation in learning. Finally, as noted above, the findings indicated that participation had the greatest influence on student motivation in learning. Lam concludes that it is essential to "clarify with students their role in learning, especially the importance of participation when using Facebook in teaching and learning" (p. 384).

\section{Negative Perspectives on SNS in the Classroom}

The use of social networking sites and Facebook in particular in education has also generated negative perspectives. To some, Facebook serves as more of a distraction than a learning tool (Wise, Skues \& Williams, 2011), which is not an unreasonable deduction since Facebook's primary use is as a social connection tool, and not an academic one. There are also some who wonder why one would choose Facebook over the ubiquitous Learning Management Systems (LMSs) already in place on most campuses, and this perspective includes both pro, con, and mixed results. For example, Meishar-Tal, Kurtz, and Pieterse (2012) studied the use of Facebook groups in the classroom and found that students expressed satisfaction with using Facebook in this manner and expressed their willingness to continue to do so in the future. Maranto \& Barton (2010) acknowledged that the opportunity for learning is present in social networking sites, and should not be ignored, yet warned of the dangers of student/teacher "friend" relationships on social networking sites, and pointed out how many students see the encroachment of education on their social network platforms as a negative experience to be avoided. Wang, Woo, Choon, Quek, Yang, and Liu (2012) found that using Facebook groups for learning resulted in overall student satisfaction accompanied with frustration over Facebook's privacy issues, and a lack of functionality for important tasks such as threaded discussions and multi-format document sharing. The use of Facebook associated with a course also brings up other problems. For example, although many students have Facebook accounts, not all do. Because it is not possible to require students to have a Facebook account, instructors that use Facebook often also use a university "sanctioned" tool such as Blackboard or Moodle. Ensuring that the LMS and Facebook are synchro- 
Magro, Sharp, Ryan \& Ryan

nized in terms of content can be laborious. This can mean double the work for the instructor. Privacy can also be an issue regarding the use of Facebook. Although Facebook does provide an option to create "secret" groups, in which no one outside the group can see who is in the group, postings or even that the group exists, some students may be reticent to join because of their country of origin or even religious reasons (Ryan et al., 2011).

Akyildiz and Argan (2012) examined the purposes for which undergraduate students used Facebook and the amount of time that they invested in these purposes. Based upon a sample of 1300 students the authors were interested in the social, daily, and educational purposes for which these students used Facebook. It was reported that of these 1300 students only $6.2 \%$ did not have a Facebook account. Not surprisingly, the results indicated that Facebook was used primarily for social and daily activities rather than for educational purposes. According to the authors, the use of Facebook for sharing information pertaining to school-related activities or for communicating with faculty is not common place. They stated that their findings are "contrary to popular claims suggesting students use Facebook for school-related works" (p. 6) and conclude "it can be said that Facebook is rarely used for educational purposes" (p. 6).

Haytko and Parker (2012) pose the question as to whether students feel that social networking sites, such as Facebook, should be used in the classroom or if they are primarily designed for social activities. In a study of 236 students from two universities of differing location and size, the authors report that the larger percentage (73.2\%) of students indicated that Facebook was not "an appropriate method for professors to use in posting course information and communicating with students" (p. 4). Reasons given by the students included: it is for "social networking, not school stuff. That's what Blackboard is for!", "students already find themselves getting off task without having their school work integrated into Facebook", students do not want professors as friends because they may have "inappropriate things on their Facebook pages" (p. 5). The authors conclude that students are not interested in friending their professors, do not want their profiles made available to professors, and in general desire to keep their social and education activities separate.

\section{Methodology}

Whereas the studies above do represent areas of current research into the use of Facebook in educational settings, there is still a limited amount of empirical research available. As such, the purpose of this study is to contribute to that research by identifying important ways that Facebook can be used to enhance educational experiences beyond that of the traditional classroom. For this study, the Delphi approach is used to gather data and rank ideas among survey respondents.

The Delphi method is a structured, multiple-round process developed to address research problems where there is no single "correct" answer. Each respondent is asked to document what he or she thinks are important ideas in dealing with the given problem. The first round, by design, is unstructured and open-ended. Thus, the purpose of the first round survey instrument is to generate relevant data related to the particular topic. The individual responses from round 1 are aggregated and a list of the ideas ispresented in round 2 . Round 2 is a quantitative round whereby each respondent is asked to rank the ideas identified by the group in terms of significance. The results of round 2 are collated, and an overall ranking is computed. In round 3, another quantitative round, the ranked factors are shown to each respondent and the respondents are given an opportunity to reevaluate their responses based on the collective and summarized results.. A consensus at some level among participants is the goal of the final round. The Delphi method has precedent in information systems research and has been used successfully (e.g., Brancheau, Janz, \& Wetherbe, 1996; Keil, Tiwana, \& Bush, 2002).

The Delphi survey was given to students in a required undergraduate introductory information systems class in the College of Business of a university in the southwestern United States. The 
class was taught a single instructor and data were collected over a three-week period (one round each week).

In this study, round 1 of the survey instrument consisted of two parts. Part 1 gathered key demographic information including age, gender, major, and family income. Additionally, it asked questions such as: "How many friends would you estimate you have on Facebook?" and "Has Facebook ever been used in one of your classes before? If yes, please describe how it was used." Part 2 instructed the participants to do the following: "Identify and briefly describe about ten ways that Facebook can be used to enhance educational experiences beyond that of the traditional classroom." Thus, the students were asked to individually brainstorm ways in which Facebook could be incorporated into the classroom. As with other Delphi studies, round 2 compiled answers from the first round and then asked: "Please rank what you consider to be the top ten ideas for using Facebook to enhance educational experiences beyond that of the traditional classroom (where 1 is the best idea, 2 is the $2^{\text {nd }}$ best, etc.)." Round 3 provided the respondents with peer rankings from round 2 and asked them to rank their top ten. They were instructed that they did not need to respond in the same way that they did in the previous rounds.

During round 1, participants completed a demographic questionnaire. The demographic information is shared here to help readers understand the suitability of the respondents for this research study. Forty-five students participated in round 1 of the Delphi study. Of this group, $62 \%$ were male and $38 \%$ were female. Only one participant was a graduate student; the remainder were undergraduates. The majority of the students were business majors, primarily in marketing, finance and accounting; however, close to one quarter of the class were non-business majors (Table 1). The participants were fairly evenly divided in regard to income bracket, the greatest percentage of participants coming from homes with an annual income of $\$ 90,000$ to $\$ 120,000$ (Table 2 ). A small percentage of participants came from homes earning less than $\$ 30,000$. One participant chose not to respond to this question.

\begin{tabular}{|l|c|}
\hline \multicolumn{2}{|c|}{ Table 1: Percentage of Students by Major } \\
\hline \multicolumn{1}{|c|}{ Major } & Percentage of Students \\
\hline Management & $04.44 \%$ \\
\hline Information Technology & $08.89 \%$ \\
\hline Decision Sciences & $02.22 \%$ \\
\hline Marketing & $22.22 \%$ \\
\hline Finance & $22.22 \%$ \\
\hline Accounting & $22.22 \%$ \\
\hline Other & $17.78 \%$ \\
\hline
\end{tabular}


Table 2: Annual Income Bracket of Students

\begin{tabular}{|l|c|}
\hline Annual Income Bracket & $\begin{array}{r}\text { Percentage } \\
\text { of Students }\end{array}$ \\
\hline$<\$ 30,000$ & $08.89 \%$ \\
\hline$\$ 30,000-60,000$ & $20.00 \%$ \\
\hline$\$ 60,000-\$ 90,000$ & $20.00 \%$ \\
\hline$\$ 90,000-\$ 120,000$ & $28.89 \%$ \\
\hline$>\$ 120,000$ & $20.00 \%$ \\
\hline No Response & $02.22 \%$ \\
\hline
\end{tabular}

According to the questionnaire, the mean number of friends on Facebook was 295.89 (Table 3). Three participants responded that they had zero friends on Facebook or that they did not have a Facebook account. Roughly $53 \%$ of participants responded as having 1 to 299 friends, whereas $40 \%$ of the class responded as having more than 300 Facebook friends. Only about $11 \%$ of participants had over 600 friends. The average number of friends reported is slightly less than the 318.5 average for 18-34 year olds reported by Pew Research (2012). It is interesting that noted anthropologist Robin Dunbar states that although you can "friend" 500, 1,000, even 5,000 people on Facebook page, it is difficult to have meaningful connections with more than about 150 . After decades of research into human social networks, Dunbar has found that one's circle of "actual" friends is limited by human nature rather than by technology.

Table 3: Number of Friends on Facebook

\begin{tabular}{|l|l|}
\hline Number of Friends on Facebook & Percentage of Students \\
\hline 0 & $06.67 \%$ \\
\hline $1-99$ & $20.00 \%$ \\
\hline $100-199$ & $11.11 \%$ \\
\hline $200-299$ & $22.22 \%$ \\
\hline $300-399$ & $08.89 \%$ \\
\hline $400-499$ & $04.44 \%$ \\
\hline $500-599$ & $15.56 \%$ \\
\hline $600-699$ & $06.67 \%$ \\
\hline $700+$ & $04.44 \%$ \\
\hline
\end{tabular}

\section{Results}

Although Facebook has become the primary social networking site, its influence has not fully penetrated the academic learning arena. Only $15.56 \%$ of participants expressed that they had used Facebook in previous classes for projects or assignments. Even so, these participants designated that they used Facebook primarily for identifying classmates and communicating with project or 
study group members. This implies that few instructors of the respondents in this sample use Facebook for educational purposes in their classes. Their use of Facebook was student-initiated and used only within the context of their group. Their activity on Facebook was not facilitated by the professor or used in any way to engage in communication with the professor or teacher's assistant (TA) (i.e., to check grades or to retrieve study guides or homework assignments). Therefore, there is certainly a need for exploration in how to apply Facebook and other social networking tools in the classroom.

Table 4, which lists the items produced by the Delphi approach, provides each item's final (third round) rank and mean score. The scores from the respondents were reverse coded (such that the best idea was a 10, 2nd best a 9, etc.) and the mean score for each idea was calculated by averaging the responses. This methodology of several rounds of scoring and averaging has been used in other Delphi studies in the past (Dickson, Leitheiser, Wetherbe, \& Nectiis, 1984).

\section{Table 4: Final Rank and Mean Score of Items}

\begin{tabular}{|c|c|c|}
\hline $\begin{array}{l}\text { Final } \\
\text { Rank }\end{array}$ & Item Description & $\begin{array}{l}\text { Mean } \\
\text { Score }\end{array}$ \\
\hline 1 & $\begin{array}{l}\text { Communicate with classmates (allows you to reach students faster, e.g., FB on } \\
\text { iPhone) }\end{array}$ & 5.91 \\
\hline 2 & Organize study groups & 5.00 \\
\hline 3 & Post test reviews & 4.28 \\
\hline 4 & Post announcements - including reminders to study for quizzes or tests & 3.67 \\
\hline 5 & Post assignments with a due date & 3.11 \\
\hline 6 & Check grades & 2.98 \\
\hline 7 & $\begin{array}{l}\text { Connect students interested in pursuing a career in that field with mentors that } \\
\text { are the professor's colleagues }\end{array}$ & 2.65 \\
\hline 8 & Send messages at any time to the instructor (ask questions, etc.) & 2.54 \\
\hline 9 & Communicate with tutor & 2.50 \\
\hline 10 & $\begin{array}{l}\text { Have professor be online at specific times each week to answer questions about } \\
\text { homework or topics in class, and make this discussion open to everyone in the } \\
\text { group (i.e., hold office hours on FB) }\end{array}$ & 2.33 \\
\hline 11 & Have class lectures on a FB account in case student misses class & 1.96 \\
\hline 12 & Share information related to class (group discussions) & 1.72 \\
\hline 13 & Use live chats so teams can discuss without having to meet & 1.70 \\
\hline 14 & Store previous exams/quizzes/sample questions & 1.63 \\
\hline 15 & Connect with businesses or professional groups in the area & 1.52 \\
\hline 16 & $\begin{array}{l}\text { Contact students from past semesters or ones taking similar courses for help or } \\
\text { tips }\end{array}$ & 1.46 \\
\hline 17 & Post videos or pictures for class research or assignments & 1.15 \\
\hline 18 & Research internships & 0.98 \\
\hline
\end{tabular}




\begin{tabular}{|c|c|c|}
\hline 19 & Post syllabus & 0.85 \\
\hline 20 & Display job postings that might be relevant to students & 0.83 \\
\hline 21 & $\begin{array}{l}\text { Incorporate sister schools and have students from different schools (or countries) } \\
\text { communicating over projects }\end{array}$ & 0.65 \\
\hline 22 & Post students opinions and class experience about a particular professor & 0.61 \\
\hline 22 & Have extra credit group discussions & 0.61 \\
\hline 23 & Surveys & 0.54 \\
\hline 23 & Identify key points that will be made during upcoming lectures & 0.54 \\
\hline 24 & Providing links to things like powerpoints, related articles, homework sites, etc. & 0.50 \\
\hline 25 & Tag people who you need further communication with & 0.43 \\
\hline 26 & Class participation on new topics each day & 0.41 \\
\hline 27 & $\begin{array}{l}\text { Allow different instructors to cover course content that is overlapping or part of } \\
\text { the curriculum for both classes }\end{array}$ & 0.37 \\
\hline 28 & $\begin{array}{l}\text { Provide an easy way for instructors to get student's information about changes or } \\
\text { updates }\end{array}$ & 0.33 \\
\hline 29 & Highlight topics in the media that are relevant to the course & 0.30 \\
\hline 30 & Exchange information about major & 0.28 \\
\hline 31 & $\begin{array}{l}\text { Serve as a backup to conventional communication (e.g., when blackboard serv- } \\
\text { ers go down) }\end{array}$ & 0.24 \\
\hline 32 & Bridge content between multiple classes with the same instructor & 0.20 \\
\hline 33 & Create interactive games on a particular chapter/project/tutorial & 0.11 \\
\hline 34 & Send out tips, funny jokes, etc. to relax students & 0.09 \\
\hline 35 & The marketplace can be used as an example for advertising & 0.02 \\
\hline
\end{tabular}

\section{Discussion}

Based upon the top 10 items in the final compiled list (Table 4), the two major suggestions for the use of Facebook in the classroom were (1) communication between various groups - between students and students, students and mentors/ professionals, students and instructors/teaching assistants and (2) information exchange in the form of notices about upcoming assignments, quizzes and tests; posting notes, test reviews and syllabi; checking grades; posting surveys, additional resources, career information and classroom materials. The importance of communication is indicated in that six of the top ten ranked items deal with some form of communication. Specifically, the top two ranked items deal specifically with using Facebook to identify and communicate with peers. Moreover, this study also indicates that communication via Facebook can be used to organize face-to-face meetings (i.e., study groups). With a reported $85 \%$ of students attending four-year universities in the United States using Facebook (Wandel, 2008), it is not too surprising that communication-related suggestions top the list. Students are surely comfortable and adept at using Facebook communication tools, such as chat, wall posts, and messages in both personal and educational settings. With readily available Internet connectivity and the growth in mobile technology and applications, communication via Facebook is on the rise. Farther down the list a sug- 
gestion is made to use Facebook for collaboration with peers, but specifically with peers from "sister schools," potentially from different countries.

Moving down the list, items 7 through 10 deal with utilizing Facebook as a primary communication tool, strengthening the communication theme. In addition to communicating with peers and being aware of class assignments and their own progress, students also place importance on using Facebook to connect with mentors in their desired field of study. This indicates that students are goal-oriented not only in the immediate academic sense, but also have broader, career objectives and a desire to use social media outlets to connect with mentors and professionals in their desired field.

Although students identified the most important objective as communicating with their peers, items 8 though 10 deal specifically with communicating with the instructor and/or teaching assistant. Facebook is quickly becoming a primary communication tool and students expect to be able to contact their professors and teaching assistants using this channel. The concept of virtual office hours emerged several years ago and recent research has been done to evaluate its utility and satisfaction among students (e.g., Li \& Pitts, 2009).

As noted above, information exchange was also a predominant theme which emerged from the results. Specifically, items 3 through 6 deal with disseminating information via Facebook about the class itself. This study indicates that students are not only seeking to identify and connect with classmates, but also desire a central information hub from which to gain knowledge about how to prepare for tests, monitor their progress, and learn what assignments and projects are coming due.

The primary focus of our analysis was on the top 10 items suggested by students. However, there were some interesting ideas that did not make the top 10 that are worth considering for their innovation and potential benefits to academic stakeholders. Some students suggested the idea of using Facebook to connect with business or professional groups in the area. Many business and groups have a presence on Facebook. Adding this kind of interaction to course assignments could provide valuable insight that students could share and discuss in class - for example, what kinds of information and experience can be gained through this sort of interaction? Another idea involved contacting students who have taken the current course in past semesters, or ones taking similar courses now, and asking them for help or tips. This would certainly need to be done with the instructor's involvement to prevent academic dishonesty, but oftentimes a past student's insight can be helpful not only to current students, but also to the instructor as it is revealed to them what their former students actually took away from the class. Another suggestion was to provide an opportunity to research internships through Facebook. For companies that have a Facebook presence, this could be beneficial to them to gauge how effective Facebook communication can be, and could even provide a proving ground for companies looking to hire interns to promote their company through social media.

The results suggest that Facebook's use in the academic arena is limited, with less than $16 \%$ of respondents indicating they have used Facebook in the classroom. Some reasons for that are Facebook's privacy policies, which many see as constantly subject to change without sufficient notice, and which are confusing to some users; Facebook's privacy limitations, such as the inability to post grades securely; Facebook's functional limitations, such as limited discussion formats and limited document sharing capability; and Facebook's professional identity, which requires users to agree to their terms before creating and maintaining an account.

Many themes provided by respondents deal with the use of Facebook as a substitute for the traditional learning management systems already employed by higher education institutions. The fitness of Facebook for this purpose is addressed in the literature review for this paper, but it is worthwhile to entertain the question of why students might prefer Facebook over a typical LMS. A definitive answer is beyond the scope of this study, but possibilities include the relative ease of 
use of both systems - Facebook is considered very easy to use, whereas some LMS are not. Also, the fact that many classes do not regularly employ the communication aspects of LMS means that students may be unfamiliar with the necessary features of the LMS, whereas most students are comfortable with Facebook through daily use. Also, although Facebook does have limitations on document sharing and some communication tools, it also offers instant messaging and certain organizational tools that some LMSs do not.

As with all research, this study is not without limitations. First is the small sample size. However, the sample size in most Delphi studies is small, and the number of respondents in the present study $(\mathrm{n}=45)$ is about the same or greater than other published Delphi studies (e.g., Keil et al. 2002). The respondents in the present study are from a university in the southwestern United States, and the results may be different in other sections of the United States or parts of the world. Delphi studies themselves are dependent upon the experiential knowledge of their respondents, and therefore are intrinsically limited and potentially flawed if the respondents have no experience with the subject matter (Powell 2002). However, only 3 respondents were not active users of Facebook, therefore we do not believe this to be the case in our study. The researchers were limited in the sense that the ideas shared by respondents were submitted in their own words without expansion or explanation, with no forum for question or clarification, and thus had the potential to be misunderstood or misrepresented by the researchers. Although we do not believe any ideas were misunderstood, the possibility may exist.

\section{Future Research}

Although using student-to faculty and student-student communications via Facebook have been researched in the past, incorporating communications with professionals and professional organizations appears to be fertile ground for future research. Future studies should investigate research questions such as, "Can social media be used as an effective vehicle for virtual mentoring?" and "If so, what are the best practices for doing so?" Also, the efficacy of some of the less common ideas, such as connecting current students with former students should be explored. Another promising suggestion was to useFacebook as a platform to allow students and businesses to connect with the purpose of ascertaining a good fit for internships. One way to approach this is to identify a business with a Facebook page that currently engages its interns through more traditional means (i.e., working with local college and university programs of study), and then creating a program where potential interns connect with company representatives through Facebook. Creating an environment where the interns are engaged in conversation over a series of relevant topics and issues related to what the company does could be part of the interview process. Researchers could interview company representatives after the fact to see if the Facebook enhanced interview process resulted in a better fit for the interns than just the traditional interview process.

\section{Conclusion}

Based upon its historical growth and usage patterns it appears that Facebook is here to stay. Since college students make up a large portion of its membership, Facebook remains a technology that may potentially be used as an effective learning tool. In previous research Facebook has been shown to assist students in both educational and cultural adaptation (Ryan et al. 2011) and this study purports to build upon those findings by identifying additional ways that Facebook can be used to enhance educational experiences in higher education beyond that of the traditional classroom. As such, this study suggests that communication and information exchange via Facebook in the classroom are of interest to students. Considering student proclivity toward using the latest available communication tools, Facebook appears to be a good match. This emphasis on communication extends to multiple constituencies including other students, faculty and teaching assistants, as well as members of the professional community. The results also indicate that the ex- 
change of course-related information is a benefit to the student. Through the use of Facebook students can review the syllabus and schedule; keep up with when exams, quizzes, and exams are due; monitor their progress; and communicate with their professor, teaching assistants, and other students in regard to preparing for exam. In sum, we believe that the results of this study can be of practical benefit to those interested in implementing the use of Facebook in an educational setting as a pedagogical/andragogical tool to foster communication and information exchange.

\section{References}

Akyildiz, M., \& Argan, M. (2012). Using online social networking: Student's purpose of Facebook usage at the University of Turkey. Journal of Technology Research, 3, 1-11.

Bowers-Campbell, J. (2008). Cyber 'pokes': Motivational antidote for developmental college readers. Journal of College Reading and Learning, 39(1), 74-87.

Brancheau, J. C., Janz, B. D., \& Wetherbe, J. C. (1996). Key issues in information systems management: 1994-95 SIM Delphi results. MIS Quarterly, 20(2), 225-242.

Dickson, G. W., Leitheiser, R. L., Wetherbe, J. C., \& Nectiis, M. (1984). "Key Information Systems Issues for the 1980's. MIS Quarterly, 8(3), 135-159.

Dunbar, R. (2010, December 25). You've Got to Have (150) Friends. New York Times. Retrieved on February 14, 2013 from http://www.nytimes.com/2010/12/26/opinion/26dunbar.html

Gilfus Education Group. (2012). Retrieved on February 15, 2013 from http://www.gilfuseducationgroup.com/top-learning-management-systems-for-20112012

Hardawar, D. (2009). Facebook ousts Google as most popular U.S. site. Retrieved July 15, 2010, from http://venturebeat.com/2010/03/15/facebook-ousts-google-as-most-popular-u-s-site/

Haytko, D. L., \& Parker, R. S. (2012). Social networking tools in a university setting: A students perspective. Journal of Instructional Pedagogies, 9, 1-9.

Irwin, C., Ball, L., Desbrow, B., \& Leveritt, M. (2012). Student's perceptions of using Facebook as an interactive learning resource at university. Australasian Journal of Educational Technology, 28(7), 12211232.

Keil, M., Tiwana, A., \& Bush, A. (2002). Reconciling user and project manager perceptions of IT project risk: A Delphi study. Information Systems Journal, 12 (2), 103-119.

Lam, L. (2012). An innovative research on the usage of Facebook in the higher education context of Hong Kong. Electronic Journal of e-Learning, 10(4), 378-386.

Lenhart, A. (2009). Pew Internet project data memo. Pew Internet and American Life Project. Retrieved on July 15,2010 , from http://www.pewinternet.org/ /media//Files/Reports/2009/PIP_Adult_social_networking_data_memo FINAL.pdf

Li, L., \& Pitts, J. P. (2009) Does it really matter? Using virtual office hours to enhance student-faculty interaction. Journal of Information Systems Education, 20(2), 175-185.

Magro, M., Ryan, K., Ryan, S. D., \& Sharp, J. H. (2012). Facebook's use in higher education. Proceedings of the Eighteenth Americas Conference on Information Systems.

Magro, M., Ryan, S. D., Sharp, J. H., \& Ryan, K. (2009). Using social networking for educational enhancement. National Decision Sciences Institute Conference.

Maranto, G., \& Barton, M. (2010). Paradox and promise: MySpace, Facebook, and the sociopolitics of social networking in the writing classroom. Computers and Composition, 27(1), 36-47.

Mazer, J. P., Murphy, R. E., \& Simonds, C. J. (2007). I'll see you on 'Facebook': The effects of computermediated teacher self-disclosure on student motivation, affective learning, and classroom climate.

Communication Education, 56(1), 1-17. 
McCarthy, J. (2012). International design collaboration and mentoring for tertiary students through Facebook. Australasian Journal of Educational Technology, 28(5), 755-775.

Meisher-Tal, H., Kurtz, G., \& Pieterse, E. (2012). Facebook groups as LMS: A case study. The International Review of Research in Open and Distance Learning, 13(4). Retrieved on January 31, 2013 from http://www.irrodl.org/index.php/irrodl/article/view/1294/2295

Orr, E. S., Sisic, M., Ross, C., Simmering, M. G., Arseneault, J. M., \& Orr, R. R. (2009). The influence of shyness on the use of Facebook in an undergraduate sample. CyberPsychology \& Behavior, 12(3), 337-340.

Pew Research. (2012, May 16). Pew Internet. Retrieved February 14, 2013 from http://pewinternet.tumblr.com/post/23177613721/facebook-a-profile-of-its-friends-in-light-of

Powell, C. (2003). The Delphi technique: Myths and realities. Journal of Advanced Nursing, 41(4), 376382.

Ross, C., Orr, E. S., Sisic, M., Arseneault, J. M., Simmering, M. G., \& Orr, R. R. (2009) Personality and motivations associated with Facebook use. Computers in Human Behavior, 25, 578-586.

Ryan, S. D., Magro, M. J., \& Sharp, J. H. (2011). Exploring educational and cultural adaptation through social networking sites. Information Technology Education: Innovations in Practice, 10, 1-16.

Salavuo, M. (2008). Social media as an opportunity for pedagogical change in music education. Journal of Music, Technology and Education, 1(2/3), 121-136.

Schonfeld, E. (2009). Facebook is now the fourth largest site in the world. Techcrunch.com. Retrieved on August 30, 2009, from http://www.techcrunch.com/2009/08/12/facebook-grew-twice-as-fast-astwitter-in-july/

Smith, J. (2010). The Facebook global monitor: Tracking Facebook in global markets. InsideFacebook.com. Retrieved on September 2, 2010, from http://www.insidefacebook.com/facebook-globalmarket-monitor/

Wang, Q., Woo, H. L., Choon, L. Q., Yang, Y., \& Liu M. (2012). Using the Facebook group as a learning management system: An exploratory study. British Journal of Educational Technology, 43(3), 428438.

Williams, J., \& Chinn, S. J. (2009). Using Web 2.0 to support the active learning experience. Journal of Information Systems Education, 20(2), 165-174.

Wise, L.Z., Skues, J. \& Williams, B. (2011). Facebook in higher education promotes social but not academic engagement. In G. Williams, P. Statham, N. Brown \& B. Cleland (Eds.), Changing Demands, Changing Directions. Proceedings ascilite Hobart 2011. (pp.1332-1342).Zuckerberg, M. (2009). A great start to 2009. Retrieved on July 10, 2012, from http://blog.facebook.com/blog.php?post=46881667130).

Wu, S., Wang, S., Liu, E. Z., Hu, D., \& Hwang, W. (2012). The influences of social self-efficacy on social trust and social capital - A case study of Facebook. The Turkish Online Journal of Educational Technology, 11(2), 246-254.

Zuckerberg. M. (2012). Facebook Press Release: Newsroom. Retrieved on November 10, 2012, from http://newsroom.fb.com/News/457/One-Billion-People-on-Facebook 


\section{Biographies}

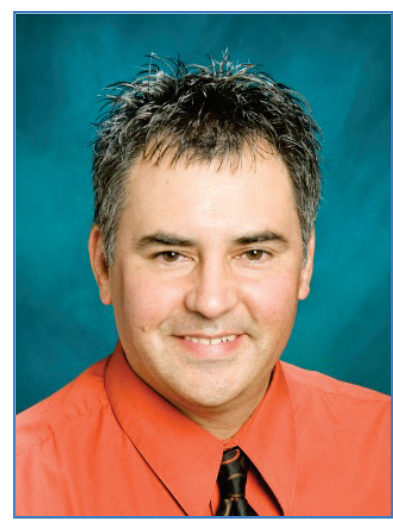

Michael J. Magro is an Assistant Professor of Information Systems and Computing Technology at Shenandoah University in Virginia. He received his Ph.D. in Business Computer Information Systems from the University of North Texas, and has a M.S. in Information Technology from the University of Redlands. Prior to returning to academia, he spent 16 years in the software development and IT solutions industry. His research interests include social networking applications, social media, hedonic information systems, IS development, and IS education and teaching. His work has appeared in Informing Science: the International Journal of an Emerging Transdiscipline, Administrative Science, the International Journal of Information and Operations Management Education, the Journal of Information Technology Education.

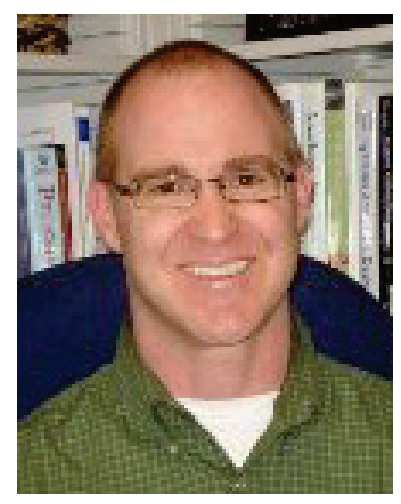

Jason H. Sharp is an Assistant Professor of Computer Information Systems at Tarleton State University. He received his Ph.D. from the University of North Texas. Prior to entering academia, he worked as a systems support specialist and developed custom database solutions for small businesses. His research interests include agile software development, social networks, course redesign, and instructional technology. His work has appeared in such journals as: Journal of Information Technology Education: Innovations in Practice, The DATA BASE for Advances in Information Systems, Journal of Information Technology Management, and International Journal of Open Source Software \& Processes.

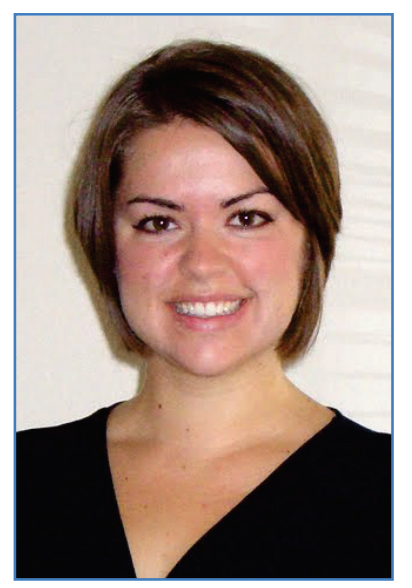

Katie Ryan is a Producer Sales Consultant for Blue Cross Blue Shield of Texas (BCBS), where she educates agents and works on internal research projects to prepare for the impending health care reform. While earning her MBA in Healthcare Administration from the University of Texas at Dallas, Katie completed research internships with both BCBS and Concentra and conducted research on using social media to promote cultural adaptation. She also worked for the Dallas Regional Chamber and served as a White House Liaison while earning a B.S. in International Business from Oral Roberts University. 


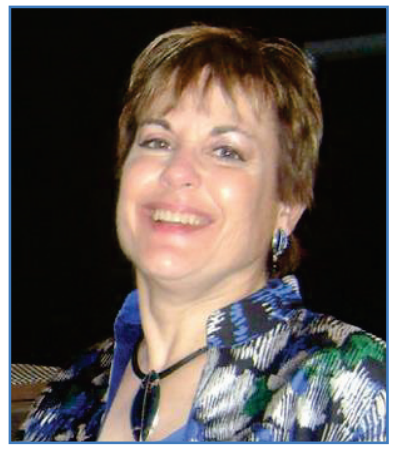

Sherry D. Ryan is an Associate Professor of Information Technology and Decision Sciences at the University of North Texas. She received her Ph.D. in IS from the University of Texas at Arlington and an MBA from the University of Southern California. Prior to returning to academia she worked for IBM, teaching courses and speaking at national conferences. Her research interests include IT human resource issues, knowledge management, and social media. Her work has appeared in journals including Journal of Management Information Systems, Decision Support Systems, and Informing Science: the International Journal of an Emerging Transdiscipline. 